\title{
NASKAH-NASKAH JUNGJANG DAN KAJIAN TEKS WASIAT SANG WALI
}

\author{
Muhamad Mukhtar Zaedin \\ Rumah Budaya Pasambangan Jati (mukhtar.rn@yahoo.com)
}

\begin{abstract}
The paper discusses one ancient manuscript stored by the Rumah Budaya Pasambangan Jati; Wahosan Bujang Genjong. Manuscript in the form of the tembang macapat tells about the figure of Bujang Genjong and Rara Gonjeng who in love. The requirement of "understanding of true knowledge" to apply for the young woman to propose the girl, in fact bringing him deeper into the nature of Sufism. In this text, Bujang Genjong is very excited to get something make him pride. The textual representation of the adventures of the youth in the pursuit of ilmu manunggal further refers to an image of the risks and responsibilities that must be borne by everyone to achieve his happiness. Culturally, what can be seen from the content of this manuscript is a culture of pre-marriage which, when viewed from the side of the prospective wife, can draw conclusions about the capacity and sincerity of her future husband. And from the prospective husband, forming the ability and fortitude to the ways and stages that must be lived and championed.
\end{abstract}

Keywords: manuscript, tasawwuf, ilmu sejati, unity (kemanunggalan)

\begin{abstract}
Abstrak
Tulisan ini membahas tentang satu naskah kuno yang disimpan oleh rumah budaya Pasambangan Jati; Wahosan Bujang Genjong. Manuskrip yang berbentuk tembang macapat ini bercerita tentang sosok Bujang Genjong dan Rara Gonjeng yang dimabuk asmara. Syarat "memahami ilmu sejati" untuk melamar yang diajukan sang pemudi kepada pemuda, ternyata membawanya semakin tenggelam dalam alam tasawuf. Dalam teks bertembang tengahan tersebut, Bujang Genjong sangat bersemangat untuk mendapatkan sesuatu yang menjadi kesenangan dan kebanggaannya. Penamsilan teks terhadap petualangan sang pemuda dalam pencarian ilmu manunggal lebih menunjukkan kepada gambaran atas resiko dan tanggungjawab yang harus di pikul oleh setiap orang untuk mendapatkan kebahagiaannya. Secara kultural, apa yang bisa dilihat dari kandungan naskah ini adalah budaya pra-pernikahan yang apabila dilihat dari sisi calon isteri, dapat mengambil kesimpulan tentang kapasitas dan kesungguhan dari calon suaminya. Dan dari sisi calon suami, membentuk kesanggupan dan ketabahan terhadap cara dan tahapan yang harus dijalani dan diperjuangkan.
\end{abstract}

Kata Kunci: manuskrip, tasawuf, ilmu sejati, kemanunggalan

\section{A. Pendahuluan}

Manuskrip atau naskah kuna adalah sebuah kekayaan intelektual yang berperan sebagai media penyampai terhadap hal-hal yang berkaitan dengan pengetahuan, adatistiadat, kebudayaan, dan keagamaan. Manuskrip mengandung

berbagai ungkapan pikiran dan
perasaan sebagai hasil budaya
bangsa masa lampau ${ }^{1}$, yang masih
memberikan informasi menarik dan
Elis Suryani, Filologi, (Bogor: Ghalia, 2012),
h. 7 . 
patut untuk dijadikan bahan penelitian oleh berbagai kalangan, terutama oleh kalangan akademisi. Karena, naskah merupakan salah satu sumber primer paling otentik yang dapat mendekatkan jarak masa lalu dan masa kini. ${ }^{2}$

Penelitian terhadap teks naskah wasiat Ruslan yang dikomentari oleh Ruknuddin Abdul Quddus al-Husain dan Abu Zakaria al-Anshari ini hanyalah sebuah penelitian kecil yang berfokus pada salah satu dari karya salah seorang tokoh tasawuf, salah satu karya seorang wali yang bernama Ruslan. Naskah ini ditemukan di daerah Desa Jungjang yang termasuk ke dalam Kecamatan Arjawinangun Kabupaten Cirebon dari salah satu pondok pesantren yang sudah tidak aktif lagi. Jadi, penelitian ini merupakan salah satu usaha untuk mengabadikan ajaran dan wasiat-wasiat beliau. Beliau adalah al-Syekh al-Wali Ruslan dari Damaskus, seorang wali yang sangat mashur dan penuh wibawa. Ilmunya yang cukup mendalam terlihat dari wasiat-wasiat beliau yang ada dalam catatan penelitian ini. Beliau adalah salah satu tokoh tasawuf yang memiliki banyak murid dan naskah ini adalah salah satu peninggalan beliau untuk mengajar kepada muridmuridnya.

Dunia tasawuf telah banyak melahirkan tokoh-tokoh besar Islam yang sangat berpengaruh dalam sejarah Islam. Tasawuf merupakan usaha untuk mencapai pembebasan pribadi lewat tauhid sejati. Tandas Hans Heinrich Schaeder dalam kesimpulannya tentang pokok ajaran tasawuf. ${ }^{3}$ Sebuah kesimpulan yang tepat dan sesuai dengan penelitian ini. Para ahli tasawuf, di samping sebagai pejuang dan bahkan menjadi tokoh sentral dalam pergerakan melawan cengkeraman kekuasaan penjajah di negeri mereka, mereka juga berperan sebagai pejuang dalam bidang penulisan karya-karya islami yang sangat produktif. Banyak sekali buku-buku yang ditulis oleh mereka dan buku-buku tersebut masih laris dan menjadi pegangan hingga kini seperti buku Ihya Ulumuddin kara alGhazali, Futūhāt al-Makkiyah karya Ibnu Arabi, dan Risalah Qusyairiyah karya Imam al-Qusyairi. Buku-buku tersebut sekalipun sudah berabadabad akan tetapi terus menjadi pembahasan dan penelitian para ahi hingga saat ini, baik dalam teks yang sudah dicetak atau pun teks-teks

\footnotetext{
3 Annemarie Schimmel, Mystical Dimensions of Islam, (Carolina: University of North Carolina Press, 1975), h. 27.
} 
yang masih dalam bentuk manuskrip (naskah kuna).

Hal itu tidak aneh karena wujud kekayaan intelektual Islam yang berkembang di masing-masing wilayah di dunia melayu Indonesia tersebut dan yang diwarisi secara turun temurun juga sangat beragam. Dan salah satunya yang cukup menonjol adalah warisan kekayaan intelektual dalam bentuk naskahnaskah tulisan tangan (manuscript). Di hampir semua wilayah yang pernah menjadi sentra peradaban Islam melayu Indonesia, naskahnaskah keagamaan yang ditulis dalam bahasa dan aksara Arab atau bahasa dan aksara lokal tersebut masih banyak dijumpai. ${ }^{4}$

Penulisan dan penelitian terkait naskah-naskah kuna akan terus berkembang sejalan dengan berkembangnya minat dan wawasan masyarakat dalam berbagai keilmuan. Naskah-naskah kuna, secara teks dan konteks, bisa didekati dengan berbagai penelitian dan kajian dengan menggunakan berbagai metodenya yang berbeda. Karena, kajian atas naskah-naskah keagamaan tersebut, baik melalui pendekatan filologis, sejarah, atau

4 Oman Fathurrahman, dkk, Filologi dan Islam Indonesia, (Jakarta: Badan Litbang dan Diklat Puslitbang Lektur Keagamaan, Departemen Agama Republik Indonesia, 2010), hlm. 9. pun berbagai pendekatan lainnya tak pelak akan memberikan kontribusi sejarah sosial-intelektual Islam $^{5}$ di berbagai wilayah dan daerah yang menjadi objek penelitian tersebut.

Naskah menjadi penting manakala sebuah penelitian tentang paham, sejarah, dan kebudayaan tidak bisa diperoleh data yang memadai dilapangan baik dari atrefak, pelaku sejarah, dan hal-hal lain yang berhubungan dengan disiplin penelitian sebuah masalah. Karenanya penelitain dan kajian ini dilakukan untuk mendorong para akademisi agar melirik ke arah sumber asli yang otentik dan masih tersebar di tengah masyarakat. ${ }^{6}$ Model penelitian dan kajian naskah ini tentunya merupakan sebuah kontribusi penting, tidak saja dunia filologi sendiri melainkan bagi dunia akademik secara keseluruhan. Bahkan, tidak berlebihan kiranya kalau pendekatan filologis yang disertai dengan analisis sejarah sosial-intelektual Islam ini akan menjadi semacam trend, khusunya di kalangan mahasiswa dan para peneliti Perguruan Tinggi Islam semisal Universitas Islam Negeri

5 Oman Fathurahman, Tarekat Syattariyah di Minangkabau: Teks dan Konteks (Shattariyyah Order in Minangkabau: Text and Context), (Jakarta: Prenada, EFEO, PPIM, KITLV, dan Total Indonesie, 2008), h. 9.

${ }^{6}$ Lihat, Suryani, Op.Cit, h. 7. 
(UIN) atau Institut Agama Islam Negeri (IAIN), seiring dengan semakin terbukanya informasi keberadaan naskah-naskah keagamaan Nusantara melalui penyusunan katalog naskah, dan semakin digemarinya kajian Islam lokal Indonesia. ${ }^{7}$

Secara kebetulan, pada tanggal 5 Juli 2011, sekelompok anggota Pengguron Lam Alif Cirebon yang di pimpin oleh Drh. H. R. Bambang Irianto, BA diantaranya Muhamad Mukhtar Zaedin, Irman Rahmat, Muhammad Shubchan, dan yang lain menemukan setumpuk naskah yang bersisi berbagai informasi tentang kebudayaan dan keagamaan. Naskah-naskah tersebut ditemukan di sebuah desa yang dekat dengan pasar, yaitu Desa Jungjang, Arjawinangun, Kabupaten Cirebon.

Naskah-naskah temuan tersebut kemudian disimpan di Pusat Konservasi dan Pemanfaatan Naskah Klasik Cirebon, Jl. Gerilyawan No. 04 Kelurahan Drajat Kecamatan Kesambi Kota Cirebon, dan menjadi milik Pengguron Lam Alif Cirebon. Kemudian naskah-naskah tersebut telah dilakukan konservasi sederhana dari penataan naskah hingga digitalisasi pada tahun 2011 dan tahun 2012. Dari jejak-jejak dan

\footnotetext{
${ }^{7}$ Fathurahman, Op. Cit. 2008.
}

hasil kegiatan pendataan dan pengkodean dapat disimpulkan bahwa jumlah naskah-naskah yang ditemukan itu mencapai 90 buah judul dengan jumlah halaman, jenis alas, tema, dan ukuran naskah yang berbeda.

Dari 90 judul manuskrip yang ditemukan, beberapa diantaranya dapat disajikan dalam sebuh tabel yang diringkas dari Katalog Naskah Koleksi Pusat Konservasi dan Pemanfaatan Naskah Klasik Cirebon tahun 2012. Ringkasan ini terdapat dalam lampiran tulisan ini.

\section{B. Naskah dan Teks}

Naskah dan teks sering dipertukarkan secara serampangan oleh sebagian orang yang tidak bisa memahami antara teks dan naskah sehingga pembahasan menjadi sulit dicerna, pada saat menguraikan teks yang ada dalam naskah. Mereka masih beranggapan bahwa teks adalah naskah itu sendiri, atau dengan kata lain bahwa naskah sama dengan teks.

Menurut Oman Fathurrahman, jika naskah merujuk pada bundel fisik dokumen kuna yang sedang kita diskusikan, maka teks adalah apa yang terkandung di dalam dokumen (naskah) tersebut, ${ }^{8}$ yang teks itu

\footnotetext{
${ }^{8}$ Fathurahman, 2010, h. 6.
} 
kandungan isinya bisa sama dengan yang ada dalam dokumen yang lain, baik di wilayah Cirebon atau pun di Nusantara.

Satu teks yang sama bisa saja ada pada beberapa naskah yang berbeda dalam wilayah atau pun tempat yang berbeda. Hal ini tidak aneh ketika melihat teks al-Quran yang bersebaran di seluruh dunia. Teks merupakan sebuah tema yang ada dalam satu naskah, bahkan satu naskah bisa memiliki beberapa teks yang berlainan tema semisal satu naskah terdiri dari beberapa teks yang isinya terdiri dari doa-doa, fikih, tahudi, dan tasawuf. Pun dalam naskah Jungjang ini, di bagian akhir naskah, ada tema fikih dengan teks yang berjudul Syarah Fath al-Qarīb yang di karang oleh Ibnu Syuja'.

Selain itu, khususnya dalam tradisi tulis dan inteletual Arab Islam, teks sesunggunya juga dibedakan kembali menjadi matan (matan), komentar (syarah), dan penjelasan (hāsyiyah). Matan adalah teks dasar utama dalam sebuah naskah yang, dalam berberapa kasus, menjadi landasan bagi seorang pengarang, bisa penulis matan itu sendiri atau orang lain, untuk menulis karya berupa syarah atau hāsyiyah atasnya matan tersebut. Model dan metode penulisan syarah bagi setia pengarang bisa berbeda satu dengan yang lain. Hal ini bisa dilihat dari hasil syarah yang dilakukan oleh Ruknuddin Abdul Qudus al-Husain dengan hasil syarah yang dilakukan oleh Abu Zakaria al-Anshari dalam memberikan komentar terhadap matan Risalah Ruslan. Perbedaan itu akan dibahas kemudian pada bab selanjutnya.

Secara umum, syarah atau hāsyiyah ditulis karena pengarang (baca: pengarang syarah atau hāsiyah, dan bukan perasaan pengarang matan, kecuali pengarang syarah atau hassyiyah dan matan itu satu orang yang sama) merasa bahwa cakupan diskusi yang terdapat dalam matan dirasa tidak memadai, terutama bagi kelompok pembaca tertentu yang membutuhkan penjelasan lebih terperinci dan mendalam yang dapat mengurai teks matan dari segi tata bahasa, tata makna, dan maksudnya yang dikehendaki oleh penulis matan. ${ }^{9}$

Risalah Wali Ruslan merupakan teks tasawuf yang diberi komentar (syarah) oleh dua orang pengarang syarah yang bernama Ruknuddin Abdul Quddus al-Husain dan Abu Zakaria al-Anshari. Syarah yang ditulis oleh Rukunuddin Abdul Quddus al-Husain diberi nama

\footnotetext{
${ }^{9}$ Fathurahman, 2010, 7.
} 
Majmaul Bahrain (Pertautan Dua Samudra) dan sedangkan syarah yang ditulsi oleh Abu Zakaria alAnshari diberi nama Fath alRahman (Gapura Sang Maha Pengasih).

Kedua teks syarah tersebut, jika melihat nama pengarangnya, berada pada tempat yang berbeda dan pada masa yang berbeda pula. Akan tetapi, penelitian ini tidak cukup waktu untuk menelusuri keberadaan tempat dari kedua pengarang syarah tersebut. Namun demikian, kedua syarah itu ada pada satu naskah Jungjang milik Pengguron Lam Alif Cirebon yang disimpan di Pusat Konservasi dan Pemanfaatan Naskah Klasik Cirebon.

Pusat Konservasi dan Pemanfaatan Naskah Klasik Cirebon sebagai tempat penelitian, sebenarnya memiliki koleksi manuskrip lebih dari 150 judul yang tentu saja dapat memakan waktu yang terlalu lama untuk teliti. Dari asal-usul manuskrip yang ada, penelitian ini akan difokuskan pada koleksi yang berasal dari temuan para anggota Majelis Dzkir Lam Alif Cirebon, seperti yang sudah disebutkan yaitu naskah Jungjang.

Kemudian setelah diketahui tema-tema yang ada dalam naskahnaskah Jungjang tersebut (seperti dalam tabel), selanjutnya pilihan dijatuhkan pada naskah Jungjang yang berkode MDLA-AWN-01A. Adapaun identifikasi singkat terhadap naskah Jungjang yang berkode MDLA-AWN-01A terlampir pada bagian akhir tulisan.

\section{Teks Tasawuf di Tempat Lain}

Saleh Partaonan Daulay telah meneliti teks Tāj al-Salātin karya Bukhari al-Jauhari koleksi Perpustakaan Nasional Republik Indonesia. Teks naskah dengan tema tasawuf berjudul Tāj al-Salātin ini ada lima naskah di Perpustakaan Nasional Republik Indonesia. Sementara perpustakaan keraton Kesultanan Yogyakarta memiliki teks naskah Tāj al-Salātin sebanyak tujuh buah naskah. Selanjutnya Daulay memberikan penjelasan bahwa teks tasawuf dengan judul Tāj al-Salātin yang ada di Perpustakaan Nasional Republik Indonesia diberi nomor dengan kode; Br. 394, Ml. 22, W. 65, Ml. 540a, dan Ml. 540b. Sementara Daulay menjelaskan bahwa naskah teks Tāj al-Salātin yang berada di perpustakaan kertaon Kesultanan Yogyakarta diberi nomor dengan kode; W. 288, W. 298, W. 290, W. 291, W. 291a, W. 291b, dan W. 291c. ${ }^{10}$

${ }^{10}$ Daulay, 2011: 69-70. 
Dalam jurnal lektur keagamaan vol. 4, no. 1, tahun 2000, Zulfikri memaparkan hasil penelitiannya dengan judul Dimensi Ajaran Tasawuf al-Palimbani dalam Kitab Sair al-Sālikīn dan Hidāyah alSālikin. Dalam penjelasannya, Zulfikri menekankan pembahasan dimensi ajaran tasawuf al-Palimbani yang berkaitan dengan ajaran-ajaran Ibnu Arabi dan al-Ghazali. Zulfikri tidak sempat memaparkan ajaran tasawuf yang lain selain wahdatul wujud yang dibahas dari awal hingga akhir. Mungkin menurut Zulfikri bahwa wahdatul wujud merupakan dimensi ajaran tasawuf yang pokok. ${ }^{11}$

Zulkarnain Yani melakukan penelitian terhadap naskah al'Urwah al-Wusthā karya alFalimbani yang menitik beratkan pada pembahasan tradisi ritual Tarekat Samaniyah di Palembang. Hasil penelitian ini kemudian diedit oleh Oman Fathurrahman dan diterbitkan pada tahun 20011 oleh Penamadani Jakarta dengan judul alUrwah al-Wusthā Karya alFalimbani: Tradisi dan Ritual Tarekat Sammaniyah di Palembang. $^{12}$

11 (Jurnal Lektur Keagamaan, Vol. 4, No. 1, 2000).

12 (Yani, 2011).
Sebelumnya

Oman Fathurrahman telah melakukan penelitian untuk disertasi di Fakultas Ilmu Budaya (FIB) yang selesai ditulis pada tahun 2003 terhadap sumber-sumber tertulis tentang tarekat Syatariyah, bagian dari tasawuf, yang kemudian hasil penelitian disertasinya diterbitkan pada tahun 2008 dengan judul Tarekat Syatariyah di Minangkabau, yang dalam penelusuran yang dilakukan olehnya sempat menyebutkan naskah-naskah kuna yang berhubungan dengan tarekat, satu ban atau bagian dari tasawuf, yang ada di Cirebon. Naskah itu adalah milik Drh. H. R. Bambang Irianto, BA atau salah satu koleksi yang dimiliki oleh Pusat Konservasi dan Pemanfaatan Naskah Klasik Cirebon. ${ }^{13}$ Dalam penelitian yang dilakukannya tentang Tarekat di Minangkabau, Oman Fathurrahman masih sempat menyinggung tentang naskah tasawuf bidang tarekat yang ada di Cirebon.

Baru-baru ini telah dilakukan penelitian terhadap naskah tasawuf yang ada di Keraton Kacirebonan yang berjudul Lajang Kawroeh Bab Kabatinan yang dalam kolofonnya naskah tersebut berjudul Hill alRumūz wa Mafätih al-Kunūz yang ditulis oleh Ibnu Arabi dan telah

${ }^{13}$ Fathurahman, 2008, 93-96. 
dicetak oleh Rumah Budaya Nusantara Pesambangan Jati Cirebon tahun 2013 dengan judul Pustaka Keraton Cirebon: Pembuka Rumus dan Kunci Perbendaharaan. Naskah tasawuf ini diterbitkan dengan edisi khusus dalam bentuk alih aksara, alih bahasa, dan edisi faksimile. Menurut keterangan yang diperoleh, pengedisian naskah kuna milik Keraton Kacirebonan dalam tiga format ini dimaksudkan untuk memberikan informasi yang utuh dalam memberikan gambaran ajaran tasawuf dalam berbagai teks bahasa yang masing-masing bahasa itu memiliki para penggunanya sendiri. Pengedisian teks naskah tasawuf dengan judul Hill al-Rumūz wa Mafātih al-Kunūz milik Keraton Kacirebonan ini dilakukan oleh Muhamad Mukhtar Zaedin dan Dr. Harapandi Dahri, M.Ag. Dalam kata sambutan dan pengantar edisi naskah ini dapat dipahami bahwa refersensi untuk sebuah kajian tasawuf terutama teks tasawuf yang berhubungan dengan paham wahadatul wujud, dalam bererapa kasus - dipandang masih sangat kurang. Banyak alasan yang dikemukakan untuk menguatkan betapa pentingnya pengedisian naskah tasawuf yang masih kaya di wilayah Cirebon.

Dalam pembukaan yang ditulis di dalam edisi teks naskah tasawuf
Hill al-Rumūz wa Mafātih al-Kunūz karya Ibnu Arabi ini dapat disajikan sebagai berikut:

"Di dalam teksnya sendiri berjudul "Hill al-Rumūz wa Mafātīh al-Kunūz: Pembuka Rumus dan Kunci Perbendaharaan, yang merupakan hasil terjemahan (translasi) dan alihaksara (transliterasi) dari Naskah Keraton Kacirebonan, yang berbahasa dan beraksara Arab, berharkat, dan bermakna Gandul (Glosari Antarbaris).

Sebuah nama, baik nama buku ini atau pun nama naskah aslinya, memberi kunci kepada kita untuk memasuki kekayaan inteletual, spiritual, dan virtual, yang luar biasa dari seorang Ibnu Arabi, yang dapat menyadarkan betapa emosi dan kecerdasan harus terus dikembangkan dan ditumbuhkan untuk mencapai kesempurnaan pengetahuan. Jika pun kesempurnaan itu merupakan kemustahilan bagi makhluk yang bernama manusia, setidaknya kita dapat mengembangkan diri dalam akal (intelektual), hati (virtual), dan rasa (spiritual) untuk lebih mendekati tujuan penciptaannya, yaitu seorang yang baik, muhsin. Dengan kata lain, menjadi orang yang berihsan seperti yang diamanatkan dalam hadis nabi yang terkenal dan sahih, 
Anta'budallāha ka annaka taraāhū, fain lam takun tarāahu, fa innahū yarāka. Yang artinya: bahwasanya kamu menyembah Allah swt seolaholah kamu melihat-Nya, jika pun kamu tidak mampu melihat-Nya, sesungguhnya Dia melihatmu.

Dari sinilah, hampir semua sufi itu mengawali pemikirannya untuk menggarap proyek revitalisasi kesucian hati sufi dengan takhalli, meruntuhkan bangunan dosa yang telah lapuk dan koyak. Sehingga tercapailah tahalli, berhias kebaikan, seperti yang telah diamanahkan oleh hadis tersebut untuk tegak dan kokohnya kerajaan hati insani, yaitu manusia yang berihsan, penuh kebaikan hakiki.

Dalam naskah ini, dengan kecerdasan akalnya, Ibnu Arabi, mampu menggugah pemahaman kita terhadap ayat dan hadis yang selama ini telah diterjemahkan secara takwili dan ditafsiri secara konvensional melalui aturan penafsiran yang baku. Sehingga, penafsiran yang dilakukan oleh Ibnu Arabi terhadap hadis dan ayat yang ada di dalam naskah ini memberikan gedung perbendaharaan makna yang betul-betul melapangkan intelektual, mencerahkan spiritual, dan menegaskan virtual yang kaya dan segar dengan penafsiran dan takwilan yang penuh dengan ide khas dan cemerlang.

Dengan kecerdasan hatinya, Ibnu Arabi membukakan tabir tipis yang menghalangi jiwa kita dengan tuntunan dzikir " $h \bar{u}$ " yang diajarkannya. Dengan kecerdasan rasanya, Ibnu Arabi merobohkan dinding sir dengan kidung cinta dan syair fana yang ditembangkan pada setiap penutupan pembahasan dan di akhir setiap pasal. Sebuah kidung yang memang penuh pujian terhadap cinta yang agung. Agung karena objek cintanya adalah Allah Yang Maha Agung.

Naskah dengan judul ini adalah naskah tunggal yang ada di Nusantara. Sehingga naskah ini menjadi naskah yang unik (Codex Unicus) karena tidak ditemukan di tempat lain, selain di Keraton Kacirebonan. Karena keunikannya itulah, naskah ini mendapatkan perhatian untuk segera diterbitkan dalam bentuk alih aksara dan alih bahasa.

Buku ini dapat menjadi rujukan pokok bagi para peneliti tasawuf, para peneliti wahdatul wujūd, dan para peneliti Ibnu Arabi yang selama ini masih merasa kekurangan dalam hal referensi yang otentik dan langsung dari sumber aslinya. 
Hal ini akan menjadi pintu yang amat luas dan lebar bagi kita untuk memasuki ranah dan alam tasawuf, terutama wahdatul wujūd, yang menjadi motor pergerakan para wali dalam penyebaran Islam di Nusantara. Jika Syekh Siti Jenar dengan wahdatul wujūdnya menuai 'petaka' di ujung keris milik Sunan Gunungjati, maka buku ini mengisahkan tentang 'petaka' yang dialami oleh Syekh Manshur alHallaj di Baghdad. Sebuah kisah yang dapat menguras seluruh kemampuan kita untuk berfikir tentang kebenaran dan kesesatan dari suatu aliran dan paham dalam Islam.

Bagaimana Ibnu Arabi melihat pengadilan wahdatul wujüd terhadap Syekh Manshur al-Hallaj, yang mungkin bisa dianalogikan untuk kasus Syekh Siti Jenar? Bagaimana Ibnu Arabi memandang kebenaran dan kesesatan dalam masalah ini? Dimana posisi pemikiran Ibnu Arabi dalam wahdatul wujūd? Dan apakah wahdatul wujūd itu? Rasanya kita perlu membaca buku ini dengan berulang kali guna menemukan jawaban yang kita harapkan, karena sebenarnya pengetahuan kita tentang masalah ini bagai sebutir debu halus yang terbang dihembus angin.

Rasanya penelitian dan kajian tentang tasawuf yang ada dalam teks naskah-nsakah Cirebon masih sangat menarik untuk dilakukan untuk memperkaya informasi yang dibutuhkan oleh para akademisi, peneliti, dan masyarakat umum atau masyarakat pengguna teks-teks tasawuf sebagai penguat informasi perkembangan Islam di Indonesia bagi penulisan sejarah dan pemikiran intelektual Islam di Nusantara. Tasawuf merupakan hal yang pokok dalam ajaran Islam, hal ini ditandai dengan tokoh-tokoh yang menjadi pergerakan Islam di Nusantara dan Jawa yang selalu diidentikkan dengan para ahli tasawuf. Bahkan tokoh besar dunia Islam yang sering disebut-sebut oleh sebagian kalangan umat Islam di Indonesia dalam berbagai ritual dan upacara keagamaan yang bernama Syekh Abdul Qadir al-Jailani adalah seorang ahli tasawuf. Bahkan beberapa naskah kuna di Museum Sri Baduga ada yang berisi tentang manaqib Syekh Abdul Qadir alJailani. Teks manaqib Syekh Abdul Qadir al-Jailani ini sebuah bukti yang nyata atas pentingnya tasawuf dalam kehidupan beragama sebagian besar masyarakat Jawa Barat, dan mungkin Nusantara pada masa lampau.

Tasawuf yang pada awalnya merupakan sebuah kesadaran terhadap Kenyataan Tunggal, yang mungkin disebut kearifan, cahaya, 
cinta, atau nihil. ${ }^{14}$ Yang kemudian ajarannya terus menerus berkembang mencangkup masalah-masalah yang dibahas dalam ilmu fikih. Hal ini tidak mengherankan karena Ibnu Arabi pun, sebagai salah satu tokoh yang terkemuka dalam tasawuf dan juga al-Ghazali, menyatukan keduanya, tasawuf dan fikih, dalam praktek ritual dan ibadah yang biasa dilakukan oleh umat Islam seharihari. Hal ini, karena setiap syariat tanpa hakikat baginya adalah kosong, dan setiap hakikat yang tanpa syariat bersamanya adalah batal. $^{15}$

\section{Selanjutnya Ibnu Arabi} merinci batasan antara tasawuf dan fikih, dalam istilah Ibnu Arabi disebut dengan syariat dan hakikat, dengan penjelasan definitif, yaitu syariat adalah mendirikan segala perintah, dan hakikat adalah menyaksikan Yang Maha Memerintah. Syariat dan hakikat itu dikumpulkan oleh dua kalimat, yaitu firman Allah swt: "Hanya Engkaulah yang Kami sembah, dan hanya kepada Engkaulah kami meminta pertolongan." (Surat alFatihah, ayat 5) "Hanya Engkaulah yang kami sembah", itulah syariat

\footnotetext{
14 Schimmel, h. 3.
}

15 Ibnu Arabi, Pustaka Keraton Cirebon: Pembuka Rumus dan Kunci Perbendaharaan, 2013: 240. dan "dan hanya kepada Engkaulah kami meminta pertolongan" itulah hakikat. ${ }^{16}$

Dalam bagian yang lain, Ibnu Arabi memaknai tasawuf ini dengan kedekatan. Kedekatan hamba kepada-Nya itu ada tiga tingkatan; kedekatan pertama adalah kedekatan badan, yaitu dengan amal. Kedekatan kedua adalah kedekatan hati dengan membenarkan dan iman. Kedekatan ketiga adalah dengan ruh dengan menyatakan dan ihsan. Kemudian alHaq, Allah swt, adalah Yang Terdekat pada biji mata manusia dari manusia itu sendiri dan lebih lekat dari selaput matanya, berada pada setiap ruang ${ }^{17}$, yang dalam bahasa hadis disebut dengan ihsan, bahwa yang dimaksud dengan ihsan yaitu bahwa kamu menyembah Allah seakan-akan akamu melihat-Nya dan jika kamu tidak melihat-Nya maka sesungguhnya Dia melihatmu (Mutafaqun 'Alaih, Hadis Shahih).

Jadi tasawuf merupakan ruh untuk menghidupkan ibadah yang dijalankan oleh umat Islam dalam mengamalkan ajaran agamanya agar selalu merasa diawasi dan dekat

16 Ibnu Arabi, Pustaka Keraton Cirebon: Pembuka Rumus dan Kunci Perbendaharaan, 2013: 241.

17 Ibnu Arabi, Pustaka Keraton Cirebon: Pembuka Rumus dan Kunci Perbendaharaan, 2013: 273. 
dengan Allah swt sebagai Dzat Yang Menjadi Tujuan penyembahan umat Islam. Hal ini tentunya yang menjadi penyebab pentingnya ajaran tasawuf sehingga melahirkan banyak karya yang pelu diteliti dan dikaji lebih lebih lanjut untuk mengungkap informasi di dalamnya.

Berbagai macam jenis penelitian bisa diterapkan untuk memperoleh hasil penelitian yang diharapkan dari subjeknya secara objektif dan adil. Dalam hal ini, studi kajian naskah merupakan hal pokok yang mesti dilakukan oleh seseorang yang menganalisa naskah. Prinsipprinsip yang digunakan dalam menganalisis naskah adalah prinsip filologi yang terdiri dari kodikologi dan tekstologi. Kodikologi adalah sebuah prinsip kajian filologi dalam menganalisis fisik naskah, sedangkan tekstologi adalah prinsip filologi untuk menganalisa teks. Adapun pendekatan yang digunakan adalah pendekatan tasawuf karena teks naskah Jungjang ini adalah naskah tasawuf.

\section{Deskripsi Naskah}

Naskah Jungjang dengan kode MDLA-AWN-01A yang diberi judul oleh pemiliknya dengan judul Naskah Jungjang Satu ini merupakan naskah yang utuh. Utuh dalam pengertian tidak terjadi kerusakan yang berarti dalam fisiknya, sehingga teks yang dalam halaman naskah juga masih terjaga dengan baik. Dari segi teks, naskah ini juga utuh karena semua teks yang ada dalam naskah ini memuat teks secara sempurna dengan muqadimah, rubrik-rubrik baru, pasal-pasal baru, hingga kolofon pada setiap teks yang ada dalam naskah ini tertulis dengan jelas. Namun demikian, ada teks terakhir yang tidak sempurna yaitu teks yang bertemakan ilmu fikih yang diberi judul Syarah Fath alQarīb. Dalam pengamatan peneliti, ketidaklengkapan teks Syarah Fathul Qarib ini lebih disebabkan karena halaman kertas yang ada dalam naskah ini sudah habis digunakan.

Bentuk teks yang digunakan dalam naskah ini adalah prosa. Jumlah baris dalam setiap halaman berisi 17 baris teks. Adapun ukuran naskah $20 \times 17 \mathrm{~cm}$ dengan ukuran teks 15 x $10 \mathrm{~cm}$. Pengarang naskah ini tidak bisa ditentukan kepada seorang pengarang karena teks yang terkandung di dalam naskah lebih dari satu. Naskah ini memuat beberapa judul teks, yaitu: 1. Dari halaman $10 \mathrm{~s} / \mathrm{d} 24$ berisi teks yang berjudul Futuhatu al-Ilahiyah, ditulis atau dikarang oleh Abu Zakaria AlAnshori, bertemakan tasawuf. 2 . Dari halaman 26 s/d 80 berisi teks yang berjudul Majma' al-Bahrain, ditulis oleh Abd al-Qudus Al-Hanafi 
Al-Husain, bertemakan tasawuf. 3 . Dari halaman 82 s/d 100 berisi teks yang berjudul Kasyfu al-Dhulmah $f i$ Bayani Furuqi Hadzihi al-Ummah, ditulis oleh Tajuddin Abu Zakaria Al-Naqsabandi Al-Usmani Al-Abasi, bertemakan tarikh. 4. Dari halaman 102 s/d 122 berisi teks yang berjudul Fathur Rohman Syarah Risalah Wali Ruslan, ditulis oleh Abu Zakaria AlAnshori, bertemakan tasawuf. 5 . Dari halaman 124 s/d 211 berisi teks yang berjudul Al-Hidayah $\mathrm{Li}$ alInsan Ila al-Karim al-Mannan Syarah al-Hikam, ditulis oleh Ali AlBayumi Al-Syafi'i, bertemakan tasawuf. Dan, 6. Dari halaman 218 s/d 228 berjudul Ghoyatu alIkhtishor Syarah al-Taqrib, ditulis oleh Abu Abdullah Muhammad ibnu Qosim Al-Syafi'i, bertemakan fikih.

Adapun penyalin dan penulisan diduga kuat dilakukan oleh Muhammad Rifa'i, seperti yang tertulis dalam kolofon yang ada pada akhir buku ini, dengan penjelasan sebagai berikut; untuk teks yang diberi judul Futuhatul Ilahiyah, selesai ditulis pada waktu Dhuha (Pagi), bulan Romadhon, tahun Alif; untuk teks yang berjudul Majma'ul Bahrain, tidak diperoleh keterangan untuk penulisannya; untuk teks dengan judul Kasyfud Dhulmah fi Bayani Furuqi Hadzihil Ummah, selesai ditulis pada waktu Dhuhur, bulan Rajab, tahun Alif; untuk teks dengan judul Fathur Rohman Syarah Risalah Wali Ruslan, selesai ditulis pada waktu Dhuhur, hari Kamis, tanggal 3, bulan Ruwah, tanpa tahun, Karang Sana, Kendal; untuk teks dengan judul Al-Hidayah Lil Insan Ilal Karimil Mannan Syarah Hikam, selesai ditulis pada waktu 'Isya, Hari Rabu, bulan Romadhon, balad (Kota) Kendal; untuk teks dengan judul Ghoyatul Ikhtishor Syarah Taqrib, tidak ada keterangan penulisan atau penyalinannya.

Selesai penyalinan terjadi pada hari Jum'at, bulan Ramadhan, tahun Alif. Tidak diperoleh angka yang pasti dari tahun, karenanya peneliti tidak bisa mengkonversikan ke dalam tahun Masehi karena tidak landasan angka yang bisa dijadikan pegangan. Tempat penyimpanan Pusat Konservasi dan Pemanfaatan Naskah Klasik Cirebon di Jl. Gerilyawan No. 04 Kelurahan Drajat Kecamatan Kesambi Kota Cirebon 45133.

Asal naskah dari KH. Halali Desa Jungjang Kecamatan Arjawinangun Kabupaten. Adapun pemilik pemilik sekarang adalah : Majelis Dzikir (Pengguron) Lam Alif yang beralamat Jl. Gerilyawan No. 04 Kelurahan Drajat Kecamatan Kesambi Kota Cirebon 45133. Sama seperti alamat Pusat Konservasi dan Pemanfaatan Naskah Klasik Cirebon. 
Jenis alas naskah Kertas Eropa dengan Cap Kertas (watermark) bergambar Singa Mahkota (Concordia). Ada garis tebal dan tipis melintang yang, jika diterawang, terlihat dan berjarak garis tebal pertama s/d keenam kirakira antara $12,5 \mathrm{~cm}$. Jumlah garis tipis dalam $1 \mathrm{~cm}$ tidak kurang dari 11 $\mathrm{cm}$. Adapun untuk memandu penulisan teks agar rapi digunakan Garis Panduan (blind line) dengan cara menekan naskah dengan sesuatu (mungkin kayu atau semacam sendok) yang digariskan pada tepian naskah.

Kondisi fisik naskah masih cukup terawat. Tulisan terbaca dengan baik. Namun demikian, naskah ini sudah lepas dari penjilidan. Penjilidan cover menggunakan kulit yang sudah terlepas dari naskah. Jumlah kuras dan lembar kertas mencapai 11 kuras yang isi masing-masing berisi 20 lembar kertas. Naskah ini tidak menggunkan penomoran halaman, akan tetapi menggunakan kata alihan yang berfungsi untuk mencari halaman sesudahnya. Jadi jumlah halaman keseluruhannya mencapai 236 halaman. Tidak ada illuminasi atau pun illustrasi yang dapat membantu penjelasan teks atau memberi latar belakang pada teks. Huruf dan bahasa yang digunakan adalah Arab. Jenis tulisan (khat) yaitu Naskhi yang cenderung ke bentuk Farisi. Warna tinta yang digunakan hitam dan merah untuk teks matan dan rubrikasi baru.

Naskah ini memuat beberapa judul teks, yaitu: teks pertama, dari halaman 1 sampai dengan halaman 9 merupakan halaman kosong. Ada tulisan dari pemilik naskah yang bukan merupakan bagian dari teks naskah, yang menceritakan tentang pemilik naskah sebelum ditemukan. Bunyi tulisan itu akan penulis singgung di bawah; teks kedua, dari halaman 10 sampai dengan halaman 24 berjudul Futuhatu al-Ilahiyah (Gerbang Ketuhanan) yang ditulis oleh Abu Zakaria Al-Anshori, bertemakan tasawuf; teks ketiga, dari halaman 26 sampai dengan halaman 80 berjudul Majma' al-Bahrain (Pertautan Dua Samudera) ditulis oleh Abd al-Qudus Al-Hanafi AlHusain, bertemakan tahuhid dengan tinjauan tasawuf. Teks judul inilah yang ada di tangan pembaca; teks keempat, dari halaman 82 sampai dengan halaman 100 berjudul Kasyfu al-Dhulmah fi Bayani Furuqi Hadzihi al-Ummah ditulis oleh Tajuddin Abu Zakaria AlNaqsabandi Al-Usmani Al-Abasi, bertemakan tarikh (sejarah firqahfirqah (sekte-sekte dalam Islam); teks kelima, dari halaman 102 samapai dengan halaman 122 berjudul Fathur Rohman Syarah 
Risalah Wali Ruslan ditulis oleh Abu Zakaria Al-Anshori, bertemakan Tasawuf. Isi teks ini juga ada di tangan pembaca; teks keenam, dari halaman 124 sampai dengan halaman 211 berjudul Al-Hidayah Li al-Insan Ila al-Karim al-Mannan Syarah alHikam ditulis oleh Ali Al-Bayumi Al-Syafi'i, bertemakan Tasawuf; dan, teks ketujuh, dari halaman 218 sampai dengan halaman 228 berjudul Ghoyatu al-Ikhtishor Syarah alTaqrib ditulis oleh Abu Abdullah Muhammad ibnu Qosim Al-Syafi'i, bertemakan fikih.

ini terdapat tulisan dengan menggunakan bolpoin yang masih agak baru. Bunyi tulisan itu adalah $l i$ afqri al-warā wa-adzli man fi alqurā haji hakam al-dīn bin haji mawardī jungjang arjawinangun cirebon (Kitab ini milik manusia terfakir dan terhina dalam kotanya, Haji Hakam al-Din bin Haji Mawardi Jungjang Arjawinangun Cirebon). Kalimat tulisan ini memberikan informasi bahwa sebelumnya naskah ini milik Haji Hakamuddin bin Haji Mawardi yang berada di Desa Jungjang Arjawinangun Cirebon Jawa Barat.

Adapun kolofon yang ada di dalam naskah terdapat beberapa kolofon, yang tersurat dalam beberapa judul teks, yang mungkin dapat menambah informasi seputar isi dan tema yang terkandung didalamnya. Untuk teks yang diberi judul Futuhatul Ilahiyah, bunyi kolofonnya: $W a$ qad faraga min naskhi ha hadza al-kitāb waqt aldhuha yaum a(l)-jum'ah syahr ramadhan sanah alif, wa shalla a(llah) 'ala khair khalqihi muhammad wa sallam, āmin, tamm. Untuk teks yang diberi judul Majma'ul Bahrain, tidak ada kolofon. Untuk isi teks yang diberi judul Kasyfud Dhulmah fi Bayani Furuqi Hadzihil Ummah, bunyi kolofonnya: tammat waqta dhuhr syahr rajab sanah alif, tamm. Teks yang di beri judul Fathur Rohman Syarah Risalah Wali Ruslan, bunyi kolofonnya: tamm al-syarhu bihamdi allah wa-'aunihi, wa-sholla allah 'ala-saŷdinā muhammadin waalihi wa-shohbihi wasallama, āmīn dāimāni fi-al-dunya wa-alakhiroh,aghfiru allah fi-al-showāb wa-al-khoto' muhammad rāfi'i, tammat fi-al-naskhi al-kitāb fathi alrahmān yaumi al-khomsi waqta dhuhrin fi syahri aruwah al-hilal tsalast wa-hadza al-kitābu fi baladi kendal fi al-dariy karang sono wa allah a'lam, shohibu al-kitāb muhammad rāfi'i faqīr haqī. Dan terakhir, untuk tek yang berjudul Ghoyatul Ikhtishor Syarah Taqrib, tidak ada kolofon sama sekali karena penulisan tidak selesai. 


\section{E. Wasiat Sang Wali Ruslan}

Secara singkat dapat disimpulkan bahwa wasiat-wasiat beliau hanya berjumlah 59 (lima puluh sembilan) buah wasiat. Dengan 59 (lima puluh sembilan) buah wasiat ini, beliau berusaha untuk mengungkapkan pokok-pokok ajaran tasawuf secara menyeluruh dengan wasiat-wasiat yang pendek namun bermakna luas.

Adapun bunyi wasiat-wasiat itu adalah sebagai berikut:

1. Keseluruhanmu adalah syirik yang samar.

2. Dan tidak akan jelas tauhidmu bagimu kecuali ketika kamu keluar dari dirimu.

3. Dan semasa kamu terlepas (dari dirimu), maka terbuka (kasyaf) padamu sesungguhnya Dia adalah Dia, dan bukan dirimu, maka kamu memohon ampunan darimu.

4. Dan ketika kamu temukan satu warna darinya (makhluk), maka syirik menjadi nyata bagimu, lalu kamu perbaharui keimanaan atau ketauhidanmu pada setiap saat dan waktu.

5. Ketika kamu keluar dari pandanganmu, maka bertambah imanmu. Ketika kamu keluar darimu, maka bertambah yakinmu. Ketika kamu keluar dari dirimu, maka kuatlah yakinmu. Wahai tahanan nafsusyahwat dan ibadat! Wahai tahanan maqam dan mukasyafat! Kamu tertipu, kamu tersibukan dengan dirimu (sehingga) jauh dari-Nya. Dimana kamu sibuk denganNya (dan) jauh dari dirimu? Dia Yang Maha Agung dan Mulia adalah Yang Maha Hadir dan Maha Melihat, Dia bersamamu dimanapun kamu berada, di dunia dan akhirat.

6. Ketika kamu bersama-Nya, maka Dia akan menghijabmu, dan ketika kamu bersamamu, maka Dia akan menjadikanmu sebagai hamba-Nya.

7. Iman adalah keluarmu dari-Nya, dan yakin adalah keluarmu darimu.

8. Dan ketika imanmu bertambah, maka kamu akan berpindah dari satu keadaan pada ke keadaan yang lain. Dan ketika yakinmu bertambah, maka kamu akan berpindah dari satu maqam (kedudukan) pada maqam yang lain.

9. Syaria'at itu untukmu hingga kamu mencarin-Nya dari-Nya untukmu, dan hakikat itu bagiNya sehingga kamu mencariNya dengan-Nya untuk-Nya Yang Maha Agung dan Mulia 
secara tak berwaktu dan tak bertempat.

10. Syari'at itu adalah batasan dan arahan, dan hakikat itu tidak ada batas dan arahnya.

11. Orang yang berdiri (beribadah) beserta syari'at (menjadi) anugerah baginya dengan mujahadah (sungguh-sugguh), dan orang yang berdiri (beribadah) beserta hakikat (menjadi) anugerah baginya dengan minnah (pemberian), sangat jauh berbedaan antara mujahadah dan minah.

12. Orang yang berdiri (beribadah) beserta mujahadah itu wujud (masih melihat dirinya), dan orang yang berdiri (beribadah) beserta minnah itu sirna (tidak melihat dirinya).

13. Amal itu berhubungan dengan syari'at, tawakal itu berhubungan dengan iman, dan tauhid itu berhubungan dengan kasyaf.

14. Manusia kebingungan dari Haq, Allah swt, dengan akal dan dari akhirat dengan hawa nafsu.

15. Ketika kamu mencari al-Haq, Allah swt, dengan akalmu, maka kamu akan tersesat, dan ketika kamu mencari akhirat dengan hawanafsumu, maka kamu akan tersesat.

16. Orang mukmin melihat dengan cahaya Allah Ta'ala, dan 'Arif
(Pengenal Allah) melihat dengan-Nya kepada-Nya.

17. Selagi kamu beserta dirimu, maka Kami perintahkan kamu, kemudian ketika kamu sirna, maka Kami walikan kamu.

18. Allah swt tidak akan menjadikan mereka (para salik) sebagai wali (kekasih) kecualai setelah mereka telah fana.

19. Selagi kamu adalah dirimu, maka kamu adalah murid (orang yang berkehendak), kemudian ketika Allah swt telah sirnakan dirimu (jauh) darimu, maka kamu adalah murad (orang yang dikehendaki).

20. Yakin abadi adalah sirnamu dari dirimu dan adamu bersama-Nya.

21. Berapa banyak antara sesuatu yang ada dengan perintah-Nya dan antara sesuatu yang ada bersama-Nya.

22. Jika kamu dengan perintah-Nya, maka asbab (segala perantara) akan tunduk padamu. Dan jika kamu dengan diri-Nya, maka akwan (segala wujud) akan patuh padamu.

23. Permulaan tingkatan maqam adalah sabar atas yang dikehendak-Nya, pertengahan maqam adalah rela dengan yang dikehendaki-Nya, dan puncak maqam adalah kamu berada dengan kehendak-Nya. 
24. Ilmu adalah jalan amal, amal adalah jalan ilmu, ilmu adalah jalan mengenal (ma'rifah), mengenal (ma'rifah) adalah jalan terbuka (kasyaf), dan terbuka (kasyaf) adalah jalan sirna (fana).

25. Kamu tidak layak bagi-Ku selagi masih ada sisa selain-Ku dalam dirimu, lalu ketika kamu singkirkan yang lain darimu, maka Aku fanakan dirimu, maka kamu (baru) patut bagi-Ku, kemudian Aku titipkan rahasiaKu padamu.

26. Ketika tidak ada gerak bagimu untuk dirimu sendiri, maka sempurna yakinmu, dan ketika tidak ada wujudmu bagimu maka sempurna tauhidmu.

27. Ahli Bathin beserta yakin dan Ahli Dhohir beserta iman.

28. Ketika hati pemilik yakin bergerak, maka berkuranglah yakinnya. Ketika tidak ada penggetar yang menggetarkan dirinya, maka sempurnalah yakinnya. Dan ketika hati pemilik iman bergerak tanpa perintah ilahi, maka berkuranglah imannya. Ketika hati pemilik iman bergerak dengan perintah ilahi, maka sempurnalah imannya.

29. Maksiat ahli yakin itu kufur, dan maksiyat ahli iman itu kurang.
30. Petakwa itu adalah pejuang, pecinta itu adalah penyerah, pengerti itu adalah penenang, dan yang diadakan itu adalah tiada.

31. Tiada diam bagi pentakwa, tiada gerak bagi pecinta, tiada kemauan bagi pengerti, tiada wujud bagi ketiadaan.

32. Cinta itu tidak akan berhasil kecuali setelah yakin.

33. Pecinta sejati hatinya telah sunyi dari selain Dia, dan selagi dalam hatinya masih ada cinta pada selain Dia, maka dia orang yang kurang cintanya.

34. Orang yang merasa nikmat dengan bencana, maka dia ada bersamanya. Orang yang merasa nikmat dengan kenikmatan, maka dia ada bersamanya. Kemudian, ketika Allah swt telah sirnakan dia dari bencana dan kenikmatan, maka hilanglah rasa nikmat terhadap bencana dan kenikmatan.

35. Pecinta tuturnya adalah hikmah, Kekasih tuturnya adalah kuasa.

36. Ibadah itu adalah untuk penggantian, dan cinta itu adalah untuk pendekatan.

37. Aku sediakan bagi hambahamba-Ku yang sholeh, sesuatu yang tidak pernah terlihat mata, tidak pernah terdengar telinga, dan tidak pernah tergambarkan dalam hati manusia. 
38. Ketika mereka mengharapkan$\mathrm{Ku}$ dengan- $\mathrm{Ku}$ untuk-Ku, maka Aku berikan mereka sesuatu yang tidak pernah terlihat oleh mata dan tidak pernah terdengar oleh telinga.

39. Ketika Allah lenyapkan dirimu dari hawa-nafsumu dengan kemurhatian dan dari kehendakmu dengan keilmuan, maka kamu akan menjadi hamba sejati; tidak memiliki keinginan dan kekuatan. Kemudian, ketika seperti itu, maka dibukakan untuk dirimu, lalu ibadah menjadi lebur luluh dalam sifat wahdaniyah, ketunggalan-Nya; sirnalah hamba dan kekallah Tuhan Yang Maha Mulia dan Agung.

40. Syari'at itu semuanya adalah kesempitan, ilmu itu semuanya adalah keluasan, dan makrifat itu semuanya adalah kepetunjukan.

41. Jalan kami adalah cinta, bukan amal; dan sirna, bukan kekal.

42. Ketika kamu masuki amal, maka dirimu untukmu. Dan, ketika kamu masuki cinta, maka dirimu untuk-Nya.

43. Penghamba selalu melihat ibadah, dan pecinta selalu melihat cinta.

44. Ketika kamu telah makrifat pada-Nya, maka adanya hembusnafasmu bersama-Nya dan gerak-gerikmu untuk-Nya. Dan, ketika kamu bodoh tentang-Nya, maka adanya gerak-gerikmu untuk dirimu sendiri.

45. Penghamba itu tidak memiliki diam, pertapa itu tidak memiliki kesenangan, pembenar itu tidak memiliki condong, dan pemakrifat itu tidak memiliki daya, kekuatan, usaha, kehendak, gerak, dan diam. Maka, yang diwujudkan itu tidak memiliki wujud.

46. Ketika kamu merasa tentram dengan-Nya, maka kamu akan merasa gelisah dengan dirimu sendiri.

47. Barangsiapa yang sibuk dengan$\mathrm{Ku}$ untuk dirinya sendiri, maka dia akan Aku butakan. Dan, barangsiapa yang sibuk dengan$\mathrm{Ku}$ untuk diri-Ku, maka sungguh dia akan Aku beri penglihatan.

48. Ketika hawa-nafsumu telah hilang, maka akan dibukakan bagimu dari pintu hakikat, kemudian sirnalah kehendakmu, kemudian dibukakan bagimu dari wahdaniyah, maka tampak nyata sesungguhnya Dia itu adalah Dia; bukan dirimu.

49. Jika kamu pasrahkan dirimu pada-Nya, maka Dia akan dekati kamu. Dan bila kamu berselisih 
dengan-Nya, maka Dia akan menjauhi kamu.

50. Jika kamu mendekatkan diri pada-Nya dengan diri-Nya, maka Dia akan mendekati dirimu. Dan jika kamu mendekatkan diri pada-Nya denganmu, maka Dia akan menjauh darimu.

51. Jika kamu mencari-Nya untukmu, maka Dia akan membebanimu. Dan jika kamu mencari-Nya karen diri-Nya, maka Dia akan memberimu petunjuk.

52. Dekatmu (dengan-Nya) adalah keluarmu dari dirimu, dan jauhmu (dari-Nya) adalah kehentianmu pada dirimu sendiri.

53. Jika kamu datang (kepada Allah swt) dengan tanpa dirimu, maka Dia akan menerima kamu. Dan jika kamu datang (kepada-Nya) karenamu, maka Dia akan menghalangimu.

54. Pengamal jarang yang lepas dari melihat amalnya, maka jadilah kamu dari sisi anugerah, bukan dari sisi amal.

55. Jika kamu mengetahui-Nya, maka kamu akan tenang. Dan, jika kamu mengasingi-Nya, maka kamu akan gelisah.

56. Yang diharapkan adalah keberadaan-Nya, yaitu Dia, dan bukan keberadaanmu, dirimu itu.

57. Kaum Awam amalannya dicurigai, Kaum Khusus amalannya pendekatan, dan Kaum Sangat Khusus amalannya kederajatan.

58. Ketika kamu jauhi nafsumu, maka kuatlah imanmu. Dan, ketika kamu jauhi dzatmu, maka kuatlah tauhidmu.

59. Makhluk semua adalah dinding, kamu adalah dinding, Allah Yang Maha Nyata tidak terdinding darimu, Dia Yang Maha Tinggi terdinding darimu olehmu sendiri, kamu terdinding darimu dengan dirimu sendiri, dan kamu terdinding darimu dengan-Nya, maka pisahkanlah dirimu darimu, niscaya kamu akan menyaksikan-Nya.

\section{F. Penutup}

Dengan melihat dan memperhatikan terjemahan teks dan konteks masyarakat yang masih berpegang teguh pada ajaran-ajaran tasawuf dan masih memerlukan bacaan untuk menjadi pegangan dalam pengamalannya, maka penelitian ini dapat disimpulkan sebagai berikut:

1. Tasawuf telah menjadi pegangan hidup sebagian masyarakat Cirebon, baik di Desa Jungjang tempat 
penemuan naskah ini atau pun di Kota Cirebon tempat konservasi naskah.

2. Risalah Ruslan dengan komentar (syarah) oleh Ruknuddin Abdul Quddus alHusain dan Abu Zakaria alAnshari adalah bagian dari teks yang ada dalam naskah Jungjang Satu.

3. Ajaran tasawuf yang ada dalam teks Risalah Wali Ruslan dengan komentar (syarah) oleh Ruknuddin Abdul Quddus alHusain dan Abu Zakaria alAnshari meliputi ajaran-ajaran tentang Syirik, Tauhid, Kasyaf, Iman, Perbedaan antara Iman dan Yakin, Hijab, Penghambaan, Tingkatan Iman dan Yakin, Pertambahan Iman dan Yakin, Perbedaaan antara Syari'at dan Hakikat, penjelasan sisi Syari'at dan Hakikat, perbedaan Mujahadah dan Minah, Perbedaan beribadah dengan Mujahadah dan Minah, hubungan Amal, Tawakal, dan Tauhid, kebingungan Akal dan Hawa Nafsu, pencarian oleh Akal dan Hawa Nafsu, perbedaan pandangan Mukmin dan Arif, perbedaan antara Wujud dan Fana, hubungan Fana dan Kewalian, perbedaan Murid dan Murad, Yakin yang Abadi, perbedaan sesama wujud, kepatuhan Asbab dan Ketundukan Akwan, perbedaan Sabar, Ridha, dan Fana, perbedaan Ilmu, Amal, Tarekat, Makrifat, Kasyaf, dan Fana, nilai Kefanaan Total, Kesempurnaan Iman dan Tauhid, Perbedaan Ahli Dhohir dan Ahli Bathin, pertambahan dan pengurangan Iman dan Yakin, masalah Maksiat Ahli Yakin dan Ahli Iman, perbedaan Mujtahid, Mutakil, Sakin, dan Mafqud, masalah perbedaan ketiadaan bagi Mutaqi, Muhib, 'Arif, dan Wujud, masalah Cinta dan Pecinta Sejati, perbedaan penikmat Bencana, Nikmat, dan Kefanaan, perbedaan Nafas Pecinta dan Kekasih, perbedaan Ibadah dan Cinta, persediaan bagi Hamba Yang Shaleh, Yang tak Terkatakan, Tersaksikan, dan Terdengar, masalah Hamba Sejati, Peleburan, dan Ketersibakan, Perbedaan Syari'at, Ilmu, dan Makrifat, masalah Jalan Cinta dan Fana, perbedaan masuk dalam Cinta dan Amal, Perbedaan Pengibadah dan Pecinta, perbedaan Makrifat dan Jahalat, perbedaan 'Abid, Zahid, Shidik, dan 'Arif, 
masalah Ketentraman dan Kegelisahan, Perbedaan Buta dan Melihat, Gerbang Hakikat dan Wahdaniyat, Perbedaan Kedekatan dan Kejauhan, masalah Pendekatan, Pencarian, sebab Kedekatan dan Kejauhan, perbedaan Diterima dan Dihijab, perbedaan Amal dan Minah, Ketenangan dan Kegelisahan, Tujuan Pokok Tasawuf, perbedaan Orang Awam, Khusus, dan Istimewa, masalah Menjauhi Hawa Nafsu dan Dzat Diri, dan terakhir tentang Hijab Makhluk, Diri, dan Allah swt sebagai kenyataan Yang Maha Nyata.

4. Naskah ini selain memuat teks Risalah Ruslan dengan komentar Ruknuddin Abdul Quddus al-Husain dan Abu Zakaria al-Anshari juga memuat teks lain yang bertemakan tasawuf seperti Syarah Hikam dan Futuhat alIlahiyah, Fikih seperti teks Syarah Taqrīb, dan sekilas paham-paham dan aliran dalam Islam seperti teks Kasyfu alDhulmah fi Bayani Furuqi Hadzihi al-Ummah yang ditulis oleh Tajuddin Abu Zakaria al-Naqsabandi alUsmani al-Abasi.
Dari penelitian ini dapat disarankan beberapa hal di antaranya:

1. Perlu diadakan perawatan naskah dengan melakukan konservasi secara serius untuk melindungi fisik naskah agar isi yang terkandung di dalamnya selalu terjaga.

2. Pelu diadakan penelitian ulang baik terkait teks yang sama atau pun terhadap teks lain yang masih ada dalam naskah tersebut.

\section{Daftar Pustaka}

Abbas, Siradjuddin, K.H., 40 Masalah Agama Jilid III, Cetakaan Kesebelas, di Cetek oleh PT. Karya Nusantara - Bandung, dan Diterbitkan oleh Pustaka Tarbiyah, Jakarta, 1985.

Arifin, Miftah, Prof., Dr., M.Ag., Sufi Nusantara: Bioghrafi, Karya Intelektual, dan Pemikiran Tasawuf, Ar-Ruz Media. Jogjakarta, 2013.

Bukhari-al, Al-Imam Abu Abdullah Muhammad bin Abul Hasan Ismail bin Ibrahim bin Bardizbah Al-Ju'fi. Matan AlBukhari Masykul (Shahih Bukhari), bahasa Arab. 4 jilid, 4 juz. Darul Kitab Al-Islami, Beirut, tanpa tahun. 
Departemen Agama RI, Al-Quran AlKarim dan Terjenahannya Dilengkapi Dengan

Transliterasi Arab-Latin, AlWajid. Diterjemahkan oleh Yayasan Penyelenggara Penerjemah Al-Qur'an. PT. Karya Toha Putra, Semarang Indonesia, Tanda Tashih tahun 1998.

Dimyati-al, Sayid Abu Bakar Al-Maki ibnu Sayid Muhammad Syatha. Kifayatul Atqiya wa Minhajul Ashfiya, bahasa Arab. Maktabah Ahmad bin Sa'd bin Nabhan, Surabaya, Indonesia, tanpa tahun.

Djamaris, Edward, Metode Penelitian Filologi, Pusat Pembinaan dan Pengembangan Bahasa Departemen Pendidikan dan Kebudayaan. Jakarta, 1991.

Fathurrahman, Oman dkk, Filologi dan Islam Indonesia, Badan Litbang dan Diklat Puslitbang Lektur Keagamaan - Departemen Agama Republik Indonesia. Jakarta, 2010.

Ghazali-al, Al-Imam Hujatul Islam Abu Hamid Muhammad bin Muhammad. Ihya Ulumuddin, bahasa Arab. 4 jilid, 4 juz. Darul Fikr, Beirut - Libanon. Cetakan ke Tiga, tahun $1141 \mathrm{H}-1991$ M.
, Kitabul Arba'in, bahasa Arab. Kurdistan, Cairo, $1343 \mathrm{H}$ - 1924 M. , Al-Kasyfu wat Tabyin, bahasa Arab. Karya Toha Putra, Semarang, Indonesia, tanpa tahun.

, Bidayatul Hidayah, bahasa Arab. Karya Toha Putra, Semarang, Indonesia, tanpa tahun.

Haderanie, K.H., H.N., Ilmu Ketuhhanan: Ma'rifat Musyahadah Mukasyafah Mahabbah 4 M, CV. Amin, Surabaya, tanpa tahun.

Hasani-al, Ilmi Zaadah Faidhullah bin Musa bin Faidhullah bin Muhammad Al-Maqdisi. Fathur Rahman lithalibi ayatil Qur'an, bahasa Arab. Darul Hikmah, Jakarta, tanpa tahun.

Ibnu Arabi, Muhyiddin Muhammad bin Ali bin Muhammad al-Arabi alThai al-Hatimi, Pustaka Keraton Cirebon: Pembuka Rumus dan Kunci Perbendaharaan, sebuah edisi teks dari naskah Hill alRumūz wa Mafātih al-Kunūz, Rumah Budaya Nusantara Pesambangan Jati Cirebon. Cirebon, 2013.

Ibnu Hajar, Al-Imam Abul Abbas Ahmad bin Muhammad bin Ali Al-Haitami. Al-Shawa'iqul 
Muhriqah 'ala Ahli al-Rafdhi wa al-Dhalaal wa al-Zandaqah al-Juz al-Tsani, bahasa Arab. Al-Resalah, Beirut - Lebanon, 1417 H - 1997.

Ibnu Qayim, Al-Imam Syamsuddin Muhammad bin Abu Bakar AlJauziyah. Madarijus Salikin, bahasa Arab. 1 jilid, 3 juz. Darul Hadis, Cairo, tahun $1426 \mathrm{H}-$ $2005 \mathrm{M}$.

Ibnu Imad, Al-Alim Al-Alamah Muhammad bin Ibrahim AlNafzi Al-Randi, Syarhul Hikam, bahasa Arab. 1 jilid 2 juz. Darul Ihyail Kutubil Arabiyah, Indonesia, tanpa tahun.

Iraki-al, Al-Alamah Zaenuddin Abul Fadhal Abdurrahim bin AlHusain. Al-Mughni an Hamalil Asfar fil Asfar fi Takhrijimaa fil Ihya minal Akhbar, bahasa Arab. 4 jilid, 4 juz. Darul Fikr, Beirut - Libanon. Cetakan ke Tiga, tahun $1141 \mathrm{H}-1991 \mathrm{M}$.

Khalidi-al, Syekh Dhiyauddin Ahmad Mustafa Al-Kamsyakhanawi AlNaqsabandi. Jami'ul Ushul fil Auliya, bahasa Arab. AlHarmain, Surabaya, Indonesia, tanpa tahun.

Khubawi-al, Usman bin Hasan bin Ahmad Al-Syakir. Durrotun Nasihin fil Wa'dhi wal Irsyad, bahasa Arab. Syirkah Al-
Ma'arif, Bandung, Indonesia, tanpa tahun.

Lubis, Nabila, Naskah, Teks, dan Metode Penelitian Filologi, Media Alo. Indonesia, 2001.

Nawawi-al, Al-Imam Muhyiddin Abu Zakaria Yahya bin Syaraf. AlArba'in Al-Nawawiyah, bahasa Arab - Indonesia. Al-Ittihad AlIslami, Malaysia, tahun $1401 \mathrm{H}$ - $1981 \mathrm{M}$.

_ , Riyadhus Shalihin min Kalami Sayidil Mursalin, bahasa Arab. Darul Fikr - Beirut, Libanon, $1400 \mathrm{H}-1980 \mathrm{M}$.

Nawawi, Syekh Muhammad Al-Jawi. Salalimul Fudhola, bahasa Arab. Maktabah Ahmad bin Sa'd bin Nabhan, Surabaya, Indonesia, tanpa tahun.

Muslim, Al-Imam Abu Husain Muslim Al-Hajjaj Al-Qusyairi AlNaisaburi. Shahih Muslim, bahasa Arab. 2 jilid, 4 juz. Darul Fikr, Beirut - Libanon, 1412 H $-1992 \mathrm{M}$.

Robson, Prinsip-prinsip Filologi Indonesia, Pusat Pembinaan Bahasa - Departemen Pendidikan dan Kebudayaan. Jakarta, 1994.

Saputra, H. Karsono, Pengantar Filologi Jawa, Penerbit Wedatama Widya Sastra. Jakarta, 2008. 
Syarkawi-al, Al-Muaqqiq Syekhul Islam Al-Syekh Abdullah bin Hujazi Al-Khalwati. Taqyidatun Lathifah 'Alal Hikam, bahasa Arab. Darul Ihyail Kutubil Arabiyah, Indonesia, tanpa tahun.

Sya'rani-al, Al-Qutub Al-Rabbani Sayidi Abdul Wahhab. Tanbihul Mughtarin, bahasa Arab. Karya Toha Putra, Semarang, Indonesia, tanpa tahun.

Syadzali-al, Al-Qutub Al-Rabbani Abul Fadhal Ahmad bin Muhammad bin Abdurrahim bin Athaillah Al-Sukandari Al-Maki. Tajul Arus fi Tahdzibin Nufus, bahasa Arab. Al-Harmain, Surabaya, Indonesia, tanpa tahun.

Tjandrasasmita, Uka, Kajian Naskahnaskah dan Penerapannya Bagi Kajian Sejarah Islam di Indonesia, Puslitbang Lektur
Keagamaan Badan Litbang dan Diklat Departemen Agama RI. Jakarta, 2006.

Turmudzi-al, Al-Imam Al-Hafidh Abu Isa Muhammad bin Isa bin Surah. Sunan Al-Turmudzi wa huwa Al-Jami'ush Shahih, bahasa Arab. 5 jilid, 5 juz. Maktabah Dakhlan, Indonesia, tanpa tahun.

Qusyairi, Abu Qasim Abdul Karim bin Hawazan al-Naisaburi, alRisalah al-Qusyairiyah fi Ilm alTasawwuf, bahasa Arab. Darul Hikmah. Beirut-Libanon, 1994.

Zabidi-al, Sayyid Muhammad bin Muhammad al-Husaini, Ittihaf al-Sādah al-Muttaqīn, 10 jilid, bahasa Arab. Muasissah alTārīkh al-Arabi. Beirut-Libanon, 1994 M - 1414 H. 


\section{Lampiran 1}

Identitas Naskah

\begin{tabular}{|c|c|c|c|}
\hline No kode & Judul & $\begin{array}{l}\text { Jenis } \\
\text { Kertas }\end{array}$ & Isi Teks Naskah \\
\hline $\begin{array}{l}\text { MDLA- } \\
\text { AWN-01A }\end{array}$ & $\begin{array}{l}\text { Naskah } \\
\text { Jungjang } 1\end{array}$ & $\begin{array}{l}\text { Kertas } \\
\text { Eropa }\end{array}$ & $\begin{array}{l}\text { Naskah ini berisi beberapa judul teks } \\
\text { yang hampir semuanya membahas } \\
\text { tentang tasawuf. Kecuali teks terakhir } \\
\text { yang berjudul Syarah Taqrīb. Teks } \\
\text { terakhir ini bertemakan fikih. }\end{array}$ \\
\hline $\begin{array}{l}\text { MDLA- } \\
\text { AWN-01 } \\
\text { B }\end{array}$ & $\begin{array}{l}\text { Syahadat } \\
\text { Fatimah }\end{array}$ & $\begin{array}{l}\text { Kertas } \\
\text { Eropa }\end{array}$ & $\begin{array}{l}\text { Berisi tentang doa-doa dan Penjelasan } \\
\text { tentang syahadat Fatimah yang berbunyi } \\
\text { : "Asyhadu anna Fatimah Al-Zahra Al } \\
\text { Karim binti Muhammad saw wa Anna } \\
\text { Fatimah Al-Zahra sayidil mar'ati binti } \\
\text { Muhammad saw". }\end{array}$ \\
\hline $\begin{array}{l}\text { MDLA- } \\
\text { AWN-02 }\end{array}$ & $\begin{array}{l}\text { Kitab } \\
\text { Sunnah as- } \\
\text { Shalah }\end{array}$ & $\begin{array}{l}\text { Kertas } \\
\text { Eropa }\end{array}$ & $\begin{array}{l}\text { Teks naskah ini menjelaskan tentang } \\
\text { tatacara shalat, bacaan dalam shalat, dan } \\
\text { wiriid setelah shalat. }\end{array}$ \\
\hline $\begin{array}{l}\text { MDLA- } \\
\text { AWN-06 }\end{array}$ & Ilmu Sharaf & $\begin{array}{l}\text { Kertas } \\
\text { Eropa }\end{array}$ & $\begin{array}{l}\text { Teks naskah ini berisi tentang ilmu } \\
\text { sharaf yang pembahasannya meliputi } \\
\text { berbagai bentuk fi'il, kata kerja, baik } \\
\text { yang mujarrad maupun yang mazid. }\end{array}$ \\
\hline $\begin{array}{l}\text { MDLA- } \\
\text { AWN-07 }\end{array}$ & $\begin{array}{l}\text { Nadham } \\
\text { Ri'ayah al- } \\
\text { Himmah \& } \\
\text { Nadham } \\
\text { Tadzkiyah }\end{array}$ & $\begin{array}{l}\text { Kertas } \\
\text { Eropa }\end{array}$ & $\begin{array}{l}\text { Teks naskah ini berisi tentang; 1)Ilmu } \\
\text { Syari'ah, Ushul Fiqh dan tasawuf; 2) } \\
\text { Hukum menyembelih dan } \\
\text { lainnya. }\end{array}$ \\
\hline $\begin{array}{l}\text { MDLA- } \\
\text { AWN-10 }\end{array}$ & $\begin{array}{l}\text { Nadham } \\
\text { Rukhshiyah }\end{array}$ & $\begin{array}{l}\text { Kertas } \\
\text { Eropa }\end{array}$ & $\begin{array}{l}\text { Teks naskah ini berisi tentang Ilmu } \\
\text { Shalat Jama' dan Qashar }\end{array}$ \\
\hline $\begin{array}{l}\text { MDLA- } \\
\text { AWN-12 }\end{array}$ & $\begin{array}{l}\text { Syair Fiqh } \\
\text { Jual Beli }\end{array}$ & $\begin{array}{l}\text { Kertas } \\
\text { Eropa }\end{array}$ & $\begin{array}{l}\text { Teks naskah ini berisi tentang } \\
\text { Penjelasan hukum jual beli. Diawali } \\
\text { dengan pembahasan tentang arti "hak } \\
\text { milik" dan dilanjutkan mulai syarat- } \\
\text { rukun hingga hal-hal yang dibolehkan } \\
\text { dan yang dilarang, dalam hal jual beli } \\
\text { secara Islam. }\end{array}$ \\
\hline
\end{tabular}




\section{Lampiran 2}

Identitas Naskah

\begin{tabular}{|c|c|c|}
\hline Judul Naskah & $:$ & Nakah Jungjang 1 \\
\hline Kode Nomor & $:$ & MDLA-AWN-01A \\
\hline Asal Usul & $:$ & $\begin{array}{l}\text { KH. Halali Hakamuddin bin Haji Mawardi bin } \\
\text { Mawardi Pesantren Baitul Hikmah, Arjawinangun }\end{array}$ \\
\hline Pemilik & $:$ & Majelis Dzikr Lam Alif Cirebon \\
\hline Tanggal Penemuan & $:$ & 5 Juli 2011 \\
\hline Tempat Penyimpanan & $:$ & $\begin{array}{l}\text { Pusat Konservasi dan Pemanfaatan Naskah Klasik } \\
\text { Cirebon }\end{array}$ \\
\hline Sampul Naskah & $:$ & warna coklat terbuat dari kulit/karton tebal \\
\hline Aksara & $:$ & Arab \\
\hline Bahasa & $:$ & Arab \\
\hline Bentuk Teks & $:$ & Prosa \\
\hline Jumlah Halaman & $:$ & 236 \\
\hline Alat Naskah & $:$ & Kertas Eropa \\
\hline Cap Kertas & $:$ & Singa Mahkota \\
\hline Cap Tandingan & $:$ & Concordia \\
\hline Ukuran Naskah & $:$ & $20 \times 16,5 \mathrm{~cm}$ \\
\hline Ukuran Teks & $:$ & $14,5 \times 9,5 \mathrm{~cm}$ \\
\hline Jumlah Baris Halaman & $:$ & 17 baris \\
\hline Tema Teks & $:$ & Tasawuf dan Fikih \\
\hline Tahun Penulisan & $:$ & $\begin{array}{l}\text { teks Futuhatul Ilahiyah selesai ditulis pada waktu } \\
\text { Dhuha (Pagi), bulan Romadhon, tahun Alif; teks } \\
\text { Kasyfud Dhulmah fi Bayani Furuqi Hadzihil } \\
\text { Ummah selesai ditulis pada waktu Dhuhur, bulan } \\
\text { Rajab, tahun Alif; teks Fathur Rohman Syarah } \\
\text { Risalah Wali Ruslan selesai ditulis pada waktu } \\
\text { Dhuhur, hari Kamis, tanggal 3, bulan Ruwah; teks } \\
\text { Al-Hidayah Lil Insan Ilal Karimil Mannan Syarah } \\
\text { Hikam selesai ditulis pada waktu 'Isya, Hari Rabu, } \\
\text { bulan Romadhon. }\end{array}$ \\
\hline Tempat Penyalinan & $:$ & Kendal, Jawa Tengah \\
\hline Kolofon & : & $\begin{array}{l}\text { Wa qad faraga min naskhi hāhadza al-kitāb waqt } \\
\text { al-dhuhā yaum a(l)-jum'ah syahr ramadhān sanah } \\
\text { alif, wa shalla a(llāh) 'alā khair khalqihi } \\
\text { muhammad wa sallam, āmin, tamm. }\end{array}$ \\
\hline Ringkasan Isi Teks & : & Naskah ini memuat beberapa judul teks, yaitu: \\
\hline
\end{tabular}




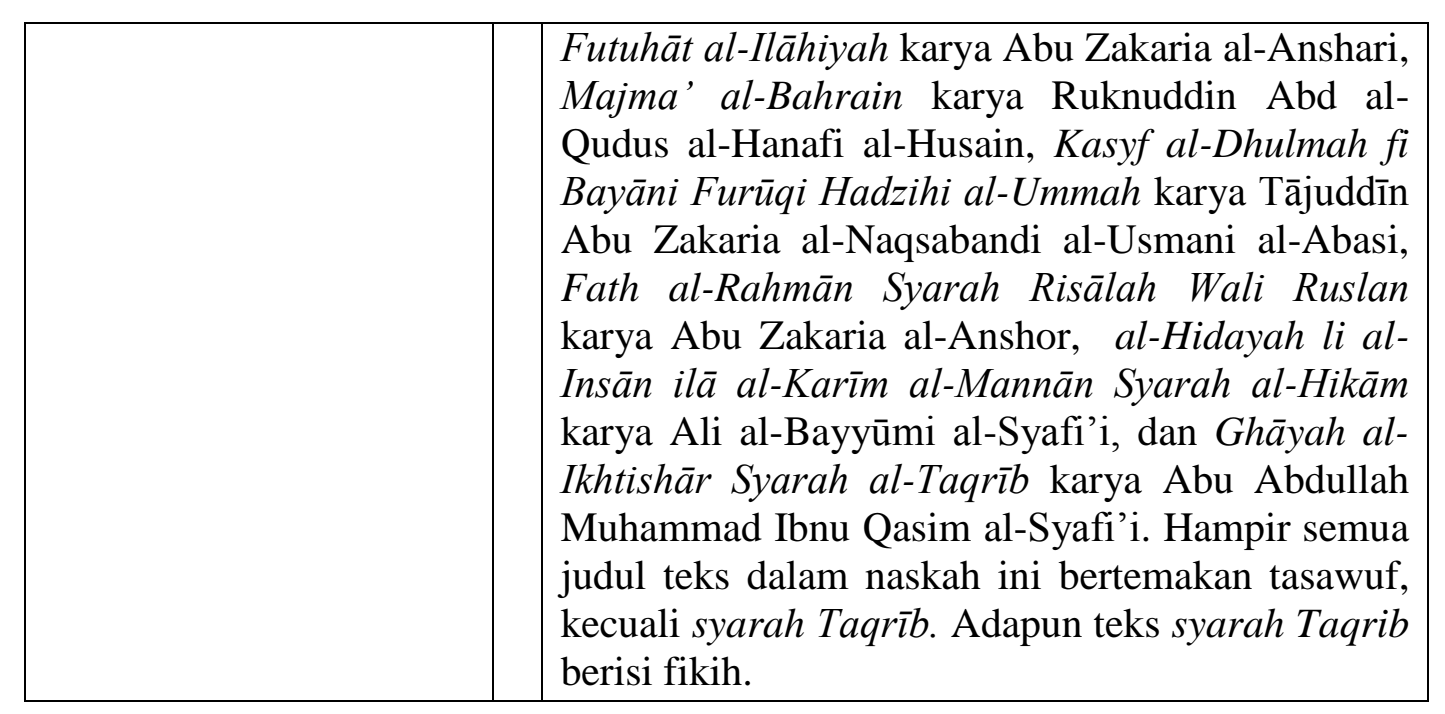

